\title{
Increased rate of acceleration on Pine Island Glacier strongly coupled to changes in gravitational driving stress
}

\author{
J. B. T. Scott, G. H. Gudmundsson, A. M. Smith, R. G. Bingham, H. D. Pritchard, and D. G. Vaughan \\ British Antarctic Survey, Cambridge, UK
}

Received: 16 January 2009 - Published in The Cryosphere Discuss.: 24 February 2009

Revised: 23 April 2009 - Accepted: 7 May 2009 - Published: 13 May 2009

\begin{abstract}
Pine Island Glacier, Antarctica, has been undergoing several related changes for at least two decades; these include acceleration, thinning and grounding line retreat. During the first major ground-based study between 2006 and 2008, GPS receivers were used to monitor ice flow from $55 \mathrm{~km}$ to $171 \mathrm{~km}$ inland, along the central flowline. At four sites both acceleration and thinning rates over the last two years exceeded rates observed at any other time over the last two decades. At the downstream site acceleration was $6.4 \%$ over 2007 and thinning was $3.5 \pm 0.5 \mathrm{ma}^{-1}$. Acceleration and thinning have spread rapidly inland with the acceleration $171 \mathrm{~km}$ inland at $4.1 \%$ over 2007 , greater than any measured annual flow increase along the whole glacier prior to 2006. Increases in surface slope, and hence gravitational driving stress, correlate well with the acceleration and no sustained change in longitudinal stress gradient is needed to explain the force balance. There is no indication that the glacier is approaching a new steady state.
\end{abstract}

\section{Introduction}

In recent decades Pine Island Glacier (PIG) has shown several changes including grounding line retreat, acceleration and thinning (Rignot, 1998; Shepherd et al., 2002; Rignot et al., 2002). The PIG basin, which comprises $10 \%$ of the West Antarctic Ice Sheet, is getting increasingly out of balance, with an estimated rate of net mass loss of $46 \mathrm{Gt} \mathrm{a}^{-1}$ in 2007 (Rignot, 2008), the greatest imbalance of any ice stream in the world. These changes may indicate the start of a period of major retreat. This could occur if the thinning causes ungrounding of the weakly grounded "ice plain" at the downstream end of PIG (Payne et al., 2004), reducing the basal resistance to flow and creating a positive feedback. It is thus important to determine precisely how thinning and acceleration are linked, how they propagate upstream, and whether there is any indication that PIG is stabilising.

Hitherto, observations of velocity change on PIG have been derived from satellite remote sensing data. In particular, Interferometric Synthetic Aperture Radar (InSAR) data have shown 10\% acceleration between 1996 and 2000 extending $100 \mathrm{~km}$ inland (Rignot et al., 2002; Joughin et al., 2003). Velocity has increased since the 1990 s, with the highest rate of acceleration recorded in 2007 (Rignot, 2008). However, the temporal resolution of InSAR is limited by satellite orbit repeat cycles. Short-term modulations of velocity, such as those caused by semi-diurnal, diurnal and fortnightly oceanic tides (e.g. Anandakrishnan et al., 2003; Bindschadler et al., 2003; Gudmundsson, 2007), cannot always be resolved, and there is a risk that some of these components may introduce bias. Also there are limited InSAR data available $>100 \mathrm{~km}$ inland, therefore it has been difficult to assess the extent of the recent acceleration. Data from GPS receivers can complement remote sensing data, giving greater temporal resolution and extending the measurements further inland. In this paper we show the first GPS measurements of velocity and acceleration on Pine Island Glacier. We also use the GPS measurements, along with ICESat data (Zwally et al., 2007), to examine recent elevation changes. The relationship between inland changes in driving stress and acceleration is examined, testing the hypothesis that recent inland acceleration may be the result of a diffusive process, where changes in surface slope are needed to transmit an initial perturbation along the ice stream over decadal timescales (Payne et al., 2004).

Correspondence to: J. B. T. Scott

(jbts@bas.ac.uk)

Published by Copernicus Publications on behalf of the European Geosciences Union. 
Table 1. Velocities and rates of acceleration measured at the GPS stations.

\begin{tabular}{|c|c|c|c|c|}
\hline Station & $\begin{array}{l}\text { Mean velocity } \\
\text { u ( } 2007 / 2008 \\
\text { season) }\end{array}$ & $\begin{array}{l}\text { Mean acceleration } \\
\text { between seasons } \\
(2006 / 2007 \text { and } \\
2007 / 2008)\end{array}$ & $\begin{array}{l}\text { Mean acceleration } \\
\text { during 2006/2007 } \\
\text { season }\end{array}$ & $\begin{array}{l}\text { Mean acceleration } \\
\text { during 2007/2008 } \\
\text { season }\end{array}$ \\
\hline PC55 & $2075 \pm 2 \mathrm{ma}^{-1}$ & $115 \pm 2 \mathrm{ma}^{-2}$ & $\begin{array}{l}137 \pm 20 \mathrm{ma}^{-2} \\
(26 \text { Dec-15 Jan) }\end{array}$ & $\begin{array}{l}131 \pm 20 \mathrm{ma}^{-2} \\
(21 \text { Nov-31 Jan) }\end{array}$ \\
\hline PC111 & $907 \pm 2 \mathrm{ma}^{-1}$ & $41.5 \pm 2 \mathrm{ma}^{-2}$ & $\begin{array}{l}49 \pm 10 \mathrm{ma}^{-2} \\
(14 \mathrm{Dec}-5 \mathrm{Feb})\end{array}$ & $\begin{array}{l}51 \pm 10 \mathrm{ma}^{-2} \\
(11 \text { Nov}-4 \text { Feb })\end{array}$ \\
\hline PC171 & $325 \pm 2 \mathrm{ma}^{-1}$ & $12.7 \pm 2 \mathrm{ma}^{-2}$ & $\begin{array}{l}11.6 \pm 2 \mathrm{ma}^{-2} \\
(19 \mathrm{Dec}-3 \mathrm{Feb})\end{array}$ & $\begin{array}{l}\text { No value } \\
(30 \text { Nov-20 Dec) }\end{array}$ \\
\hline PS169 & $319 \pm 2 \mathrm{ma}^{-1}$ & & Not deployed & $\begin{array}{l}\text { No value } \\
\text { (1 Dec-30 Dec) }\end{array}$ \\
\hline
\end{tabular}

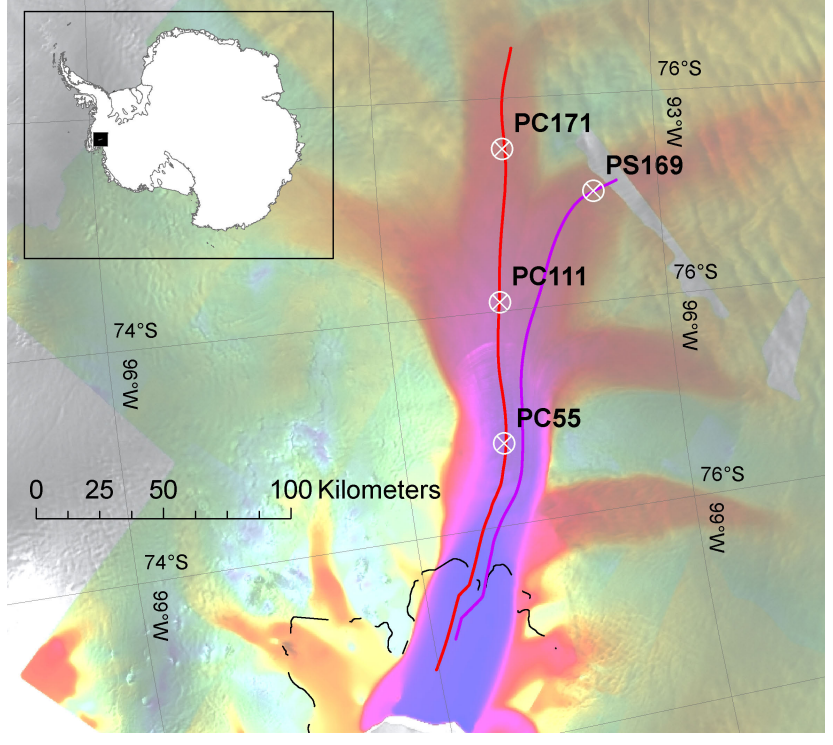

Fig. 1. Map of Pine Island Glacier. Flowlines in red and purple; grounding line (2000) in black. Background is velocity magnitude from ERS-1/-2 data overlaid on a RADARSAT-1 mosaic (Rignot, 2006).

\section{Observations}

Between early-December 2006 and early-February 2007, three GPS receivers were sited close to the central flowline of PIG (Fig. 1) at sites 55, 111, and $171 \mathrm{~km}$ upstream from the grounding line (the 2000 flexing limit determined from InSAR, E. Rignot, personal communication, 2007). The same geographic sites (hereafter PC55, PC111 and PC171 respectively), were reoccupied between mid-November 2007 and early-February 2008, and a further GPS station, PS169, was placed on a tributary to PIG, $169 \mathrm{~km}$ upstream from the grounding line (Fig. 1).
GPS data were recorded at $10 \mathrm{~s}$ intervals and processed to give kinematic precise point position solutions every $30 \mathrm{~s}$. This processing used the Bernese software and was the same as that used by Gudmundsson (2007). With this method it is possible to detect variations in horizontal position to around $0.01 \mathrm{~m}$. A more detailed analysis of this processing method and the associated uncertainties is given by Dach et al. (2009).

At the beginning and end of the 2007/2008 season, further GPS measurements were made to derive the strain rates in a $1 \mathrm{~km}$ radius around each site. The surface profile along the central flowline was also measured by kinematic GPS, along with net snow accumulation at PC55 and PC111.

\section{Mean velocity and acceleration}

The mean velocity for the austral summer season, 2007/2008, is given in Table 1, for all GPS sites; along with mean acceleration over both seasons (2006/2007 and 2007/2008) and over the between-season period. The measurement period at PS169 was too short to provide an accurate estimate of acceleration. All accelerations have been corrected for the effect of spatial gradients in the velocity field by using the local strain rate estimates. Velocities and accelerations shown in Table 1 were calculated by fitting a quadratic function of time to in-line displacements for each measurement period. The uncertainty in the quadratic fit is the largest error in the calculation of the acceleration, these errors are given in Table 1. Acceleration was nearly constant, although some residuals between measured and fitted displacements indicate shortterm changes of velocity. The greatest of these changes are discussed later. Table 1 shows that the acceleration at PC55 was $>130 \mathrm{ma}^{-2}$ in both seasons, with a mean acceleration between the seasons of about $115 \mathrm{ma}^{-2}$. Therefore the summer acceleration appears slightly higher than the annual acceleration, although this difference is within the error limits (Table 1). 
We can only compare the GPS velocity directly with a recent InSAR measurement at PC55, where an InSAR velocity estimate is available 124 days before the midpoint of the 2006/2007 GPS occupation (E. Rignot, personal communication, 2007). The GPS velocity can be corrected for the time difference between these measurements, using the acceleration measured by the GPS. This gives a velocity of $2.7 \%$ greater than the InSAR velocity. InSAR velocities can have errors up to $3 \%$ in areas of high slope, which tend to cancel out when comparing several InSAR data sets with similar imaging geometry (I. Joughin, personal communication, 2007). This error and changes in acceleration could account for the difference between the GPS and InSAR.

For all GPS sites, velocity estimates for the year 1996 are available from InSAR (Joughin et al., 2003). Compared to these earlier estimates, velocities have increased significantly. The increases over the 12 -year period from early 1996 to mid-season 2007/2008 at PC55, PC111, PC171 and PS169 are 42\%, 36\%, 34\% and 26\% respectively, approximately a 2 to $3 \%$ annual increase. The velocity increases at PC55, PC111 and PC171 during 2007 were 6.4, 4.8 and $4.1 \%$ respectively. Thus, over the entire length of PIG, acceleration during 2007 was considerably larger than over the 12-year period from 1996 to 2008.

The velocity increase of $42 \%$ over 12 years at PC55 is identical to that reported by Rignot (2008), from InSAR measurements alone, for the area close to the grounding line (around $40 \mathrm{~km}$ downstream from PC55). The 2007 rate of acceleration at PC55, of 6.4 over 12 months, is slightly higher than that reported by Rignot (2008), of $8 \%$ over 16 months, but this is likely to be due to the difference in time period. This demonstrates that where the GPS measurements and InSAR overlap they are in good agreement despite the difference in spatial scales. However, the GPS results also demonstrate velocity increases further upstream than has been possible using the available InSAR data, which, apart from in 1996, do not have the spatial coverage to give velocity estimates further than around $100 \mathrm{~km}$ inland on PIG.

\section{Elevation change}

At each GPS site, we calculated a thinning rate $\left(\partial_{t} h\right)$ for the continuous measurement periods, from the speed in the direction of flow $(u)$, the vertical speed $(w)$, the surface gradient in the direction of flow $\left(\partial_{x} h\right)$ and the rate of accumulation (a) using the kinematic boundary condition

$\partial_{t} h+u \partial_{x} h-w=a$.

Contributions to uncertainty in the calculated thinning rates arise from GPS measurements of $u$ and $w( \pm 1 \%)$; the standard error in the surface gradient measurement (from the GPS profiles $\pm 7-9 \%$ ) and the variation in the accumulation rate. Accumulation was measured against snow stakes at PC55 and PC111, giving 0.99 and $1.06 \mathrm{ma}^{-1}$ respectively.

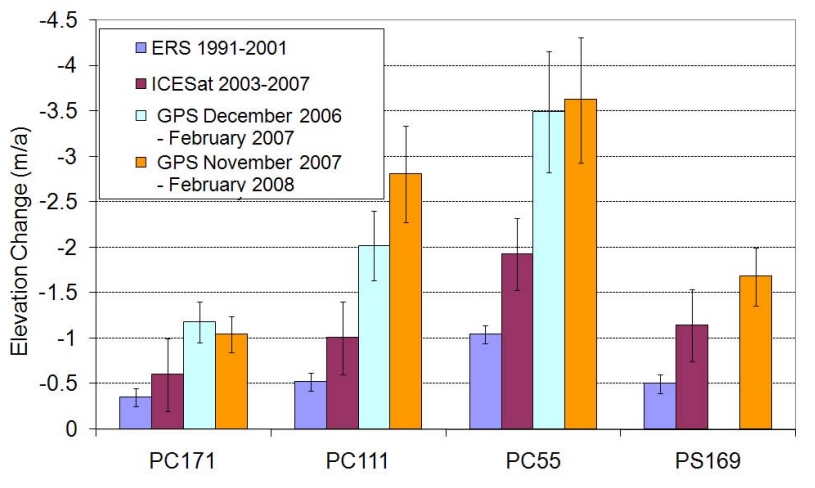

Fig. 2. Rates of elevation change from GPS measurements, laser altimetry (Appendix A) and radar altimetry (Shepherd et al., 2002).

These accumulation measurements agree closely with mean values from five $20 \mathrm{~m}$ ice cores taken at PC111, PC171 and sites in between during the 2006/2007 and 2007/2008 seasons. From these cores we calculate a standard deviation in the annual accumulation rate of $\pm 20 \%$.

There is a decrease in surface elevation during both seasons at all the GPS sites. This can be compared with elevation change derived for the same sites using satellite laser altimetry, calculated by us from ICESat data (Appendix A), for the period 2003-2007 (Fig. 2). For the ICESat elevation changes we have calculated errors due to the measurements not being at the same location as the GPS stations, using the standard deviation in the ICESat estimates over a $10 \mathrm{~km}$ radius. Taking ICESat elevation change values along a $10 \mathrm{~km}$ profile, perpendicular to, and crossing, the ice stream centerline shows that there is no significant elevation change bias due to the GPS points being located along this centerline. We compare these ICESat elevation changes to those derived from satellite radar altimetry for the period 19912001 (Shepherd et al., 2002) (Fig. 2). Figure 2 shows that the thinning is increasing, and that it is strongest close to the grounding line. Our analysis of ICESat data is consistent with the earlier ICESat results presented by Thomas et al. (2004b) which showed that during 2004 thinning was approximately double that of the 1990s. Current rates of thinning (late 2006 to early 2008) from GPS are even higher at around three times greater than in the 1990s.

\section{Relationship between thinning and acceleration}

The thinning rates (Fig. 2) demonstrate that PIG is steepening at an increasing rate. The rate of slope increase over the central region of PIG between PC55 and PC171 was found to be approximately constant at $2.06 \times 10^{-5} \mathrm{a}^{-1}$ during the $2006 / 2007$ season and $2.28 \times 10^{-5} \mathrm{a}^{-1}$ for $2007 / 2008$. To examine the first order relationship between the steepening and 
acceleration we use a force balance for the glacier where the centerline velocity $(u)$ is given by (van der Veen, 1999)

$u=\frac{2 A}{n+1} H\left(\hat{\tau}_{d}\right)^{n}\left(\frac{W}{2 H}\right)^{n+1}$,

where, $H$ is ice thickness, $W$ is ice-stream width, and $A$ and $n$ are material properties describing ice flow. Here, $\hat{\tau}_{d}$, is the effective driving stress which is a combination of the gravitational driving stress, $\tau_{d}$, the basal drag, $\tau_{b}$, and the gradient in longitudinal stress. Implicitly, we have assumed that basal shear stress is independent of width and that horizontal stress gradients are small compared to both side and basal drag. These assumptions are made to provide a first order analysis and are a starting point for evaluating the potential effects of slope changes on centerline velocity. A similar model was applied by Joughin et al. (2003) and by Thomas et al. (2004a) for estimation of basal stress.

We apply Eq. (2) to the average geometry over the 116$\mathrm{km}$ central flowline of PIG between PC55 and PC171, calculating the gravitational driving stress from the surface slope $(\alpha=-0.00135)$, ice density $\left(\rho=917 \mathrm{~kg} \mathrm{~m}^{-3}\right)$, gravitational acceleration $\left(g=9.81 \mathrm{~ms}^{-2}\right)$ and ice thickness $(H=1860 \mathrm{~m})$ using

$\tau_{d}=-\rho g H \sin \alpha$,

to give, $\tau_{d}=22.6 \mathrm{kPa}$. From our strain rate measurements at PC55 and PC171 we calculate the longitudinal stresses, giving a net stress due to longitudinal stress gradients of $-1.5 \mathrm{kPa}$ for this region, approximately $7 \%$ of the magnitude of the gravitational driving stress and acting in the opposite direction. We use $n=3$ and $A=2.9 \times 10^{-16} \mathrm{~s}^{-1} \mathrm{kPa}^{-3}$, corresponding to a depth-averaged temperature of $-15^{\circ} \mathrm{C}$ (Paterson, 1994), and estimate an average $W=44 \mathrm{~km}$. From the speed at PC111, approximately the midpoint of this section of flowline, accounting for the additional resistance from the longitudinal stress gradient, from Eq. (2) we calculate a basal drag of $3.6 \mathrm{kPa}$. This is low compared to the driving stress and therefore our use of Eq. (2) as a first order model is further justified.

With an initial assumption that basal drag and longitudinal stress gradients do not change, we analyse the sensitivity of velocity to changes in gravitational driving stress alone. We also assume ice thickness $(H)$ to be constant. This approximation works because changes in absolute thickness have an order of magnitude less effect on the driving stress than the surface slope changes over this period. These assumptions are made only in order to assess whether these changes in driving stress are sufficient to account for the rates of acceleration observed over this portion of the ice stream. Substituting Eqs. (3) into (2), differentiating with respect to time, and noting that $\alpha \ll 1$, we find

$\partial_{t} u=D \cdot u^{((n-1) / n)} \cdot\left(\partial_{t} \alpha\right)$,

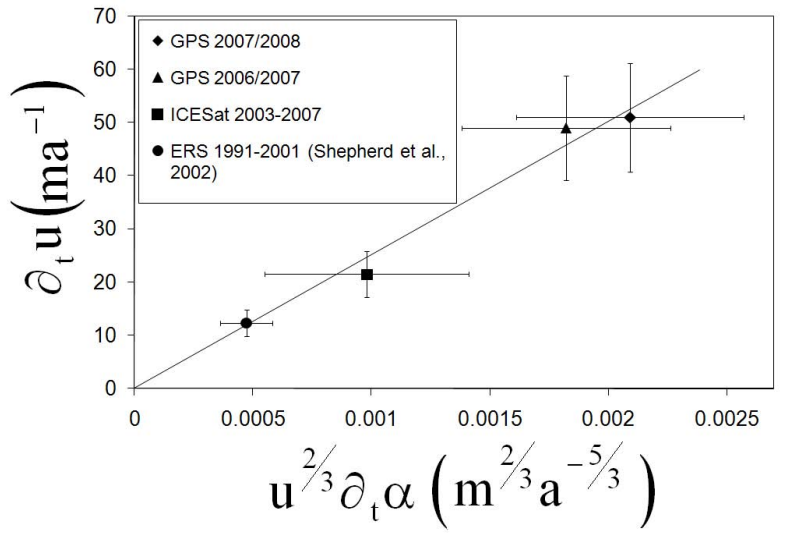

Fig. 3. Graph of $\partial_{t} u$ against $u^{2 / 3} \partial_{t} \alpha$. Average slope changes for 1991-2001 from Shepherd et al. (2002) and for 2003-2007 from ICESat (Appendix A). With December 2006-February 2007 and November 2007-February 2008 calculated from GPS measurements. The black line is the best fit to the data.

where the constant,

$D=n\left(\frac{2 A}{n+1}(\rho g)^{n}\left(\frac{W}{2}\right)^{n+1}\right)^{\frac{1}{n}}$.

The average rate of slope increase $\left(\partial_{t} \alpha\right)$ between the same points for $1991-2001$ was $0.60 \times 10^{-5} \mathrm{a}^{-1}$ (from satellite radar altimetry: Shepherd et al., 2002) and for 2003-2007 was $1.15 \times 10^{-5} \mathrm{a}^{-1}$ (calculated by us from ICESat laser altimetry data). For the periods over which we have GPS measurements, the directly calculated values of $\partial_{t} u$ and $u$ can be used. For earlier periods the average rate of velocity increase $\left(\partial_{t} u\right)$ can be estimated for the central point (PC111). This is done by subtracting the annual percentage accelerations estimated by InSAR (Joughin et al., 2003; Rignot, 2006), and accounting for the fact that PC111 has had a lower percentage increase, at $6 \%$ less than PC55 over the 12-year period from 1996. Figure 3 shows the data, paired values of $\partial_{t} u$ plotted against $u^{2 / 3} \partial_{t} \alpha$. The best fit gives $D=25400\left(\mathrm{ma}^{2}\right)^{1 / 3}$ with an $R^{2}$ coefficient of determination of 0.99 . When calculated using the estimated values for ice stream width and the material parameters given above, $D=27600\left(\mathrm{ma}^{2}\right)^{1 / 3}$. However, this small difference is within the uncertainties in the parameters and could be achieved simply by changing $W$ from $44 \mathrm{~km}$ to $41 \mathrm{~km}$ in Eqs. (4) and (5). The strength of the correlation with the acceleration (Fig. 3) is entirely due to the slope changes, and hence changes in gravitational driving stress, this is because $u^{2 / 3}$ increases by only $19 \%$ over this time period, which would not give a significant correlation, whilst $\partial_{t} \alpha$ increases by $271 \%$. We conclude that available observations over the past 18 years conform to this simple model and relate the surface slope increases directly to acceleration along this section of PIG. To a first order we do 
not need additional force balance changes from longitudinal stress gradients or basal drag. However, we cannot neglect the effect of perturbations in these stresses, particularly from the downstream end of PIG, which models have shown may initiate the related velocity changes and inland thinning (Payne et al., 2004; Thomas et al., 2004a).

\section{Short term variations}

Tidal analysis of horizontal and vertical displacements was performed using the software t_tide (Pawlowicz et al., 2002) but, despite 2-3 months high-precision GPS records, no measurable tidally-induced variation in flow could be detected at any of the sites, including nearest to the grounding line at PC55. The lack of tidal velocity modulation gives more confidence in velocities estimated from InSAR processing and increases confidence that comparison of InSAR and GPS velocities is reasonable.

For the 2006/2007 season the accelerations at all sites were approximately constant; that is, after removing a constant acceleration component from the flow-direction displacements the residual displacements were around GPS error levels. However, for the 2007/2008 season, after removing a constant acceleration component, significant residuals remained at PC55 and PC111. Residuals at PC171 and PS169 were smaller than those at PC111 by a factor of 5, and than those at PC55 by a factor of 15 . These residuals were therefore close to noise level, and along with the shorter observation periods at PC171, and PS169, meant that analysis was not possible. For easy comparison between PC55 and PC111, the residuals have been normalized by the total horizontal displacement at each station and are displayed in Fig. 4.

The short term changes at PC55 and PC111 are closely matched (Fig. 4). We cannot identify a phase-shift between the two curves due to GPS noise, hence the response effectively appears instantaneous. However, we estimate an uncertainty of two days. These short-term acceleration changes observed at PC55 and PC111 were not accompanied by any fluctuations in the vertical positions of the stations, signifying no coincident fluctuations in gravitational driving stress. However, there were fluctuations in the strain rate, and hence changes in the longitudinal stress gradient between the two stations, with the same time period as the fluctuations in acceleration observed individually at each station. Therefore these changes in acceleration have been transmitted instantaneously by longitudinal stresses. The perturbations may originate from the grounding line, ice shelf or from changes in the basal conditions, including the movement of subglacial water. However, these fluctuations in the longitudinal stress gradient are at a lower order of magnitude than the longer term increases in driving stress.

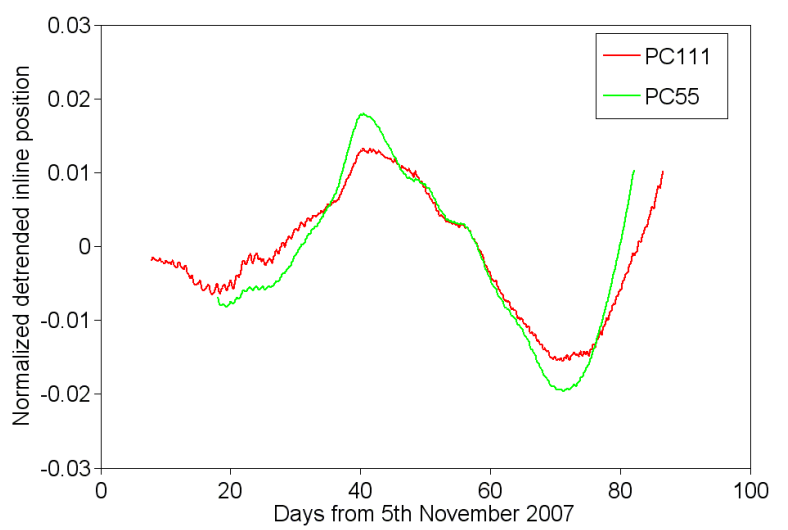

Fig. 4. Horizontal inline flow-direction positions for PC55 and PC111 de-trended by a quadratic (constant acceleration component removed) and normalized by dividing by the total distance travelled in one day at each location.

\section{Discussion}

The GPS measurements reveal that the rates of acceleration experienced in 2007, which are higher than any previous measurements have shown on PIG, extend far inland. At the downstream end of PIG, the acceleration reached at least $6.4 \% \mathrm{a}^{-1}$ in 2007 , but it was also 4.8 and $4.1 \% \mathrm{a}^{-1}$ at distances of 111 and $171 \mathrm{~km}$, from the grounding line, respectively. This upstream acceleration is at a greater percentage rate than any estimates prior to 2006 for the downstream end of the glacier (Rignot, 2006). The current high acceleration phase of PIG may have started in 2002, there is little acceleration from 2001 to 2002 followed by very high acceleration from 2002 onwards (Rignot, 2006). But even if it started around 1996 (Joughin et al., 2003) and the perturbation causing this acceleration originated at the downstream end of the glacier it is likely that it has been transmitted rapidly upstream, by a diffusion process, faster than the 10 years per $100 \mathrm{~km}$ suggested by the model of Payne et al. (2004). The reduction in the percentage velocity increases, with distance upstream, suggests that the perturbation could originate at the downstream end of the glacier, but modelling is needed to verify this.

Current rates of thinning are higher than over the previous two decades. If the exceptionally high thinning rates continue they could contribute to ungrounding of the weakly grounded ice plain and further acceleration (Thomas et al., 2004a; Payne et al., 2004). The section of PIG, 55 to $171 \mathrm{~km}$ inland, is steepening at a rate which provides an increase in driving stress of sufficient magnitude to produce the observed acceleration. There does not necessarily need to have been a sustained increase in longitudinal stress gradient or reduction in basal drag over this region of the glacier to explain the current force imbalance. However, we have measured 
changes in the longitudinal stress gradients that are transmitted rapidly along the glacier causing fluctuations in the acceleration over short periods at sites $56 \mathrm{~km}$ apart. It is likely that perturbations transmitted initially by longitudinal stress gradients cause the acceleration inland (Payne et al., 2004; Thomas et al., 2004a).

\section{Conclusions}

The GPS measurements on PIG augment those obtained from remote sensing. They demonstrate that rates of thinning and acceleration are both increasing and that this extends at least $171 \mathrm{~km}$ inland. Acceleration is highly correlated to slope increase and no sustained increase in longitudinal stress gradient, or decrease in basal drag, is needed to explain the force balance. Transmission of the acceleration inland has been exceptionally fast at around $200 \mathrm{~km}$ per decade, or possibly even quicker. The results are consistent with the hypothesis that changes in PIG result from changes at the downstream end, including the grounding area and floating ice shelf. It appears that PIG is not only out of balance but continues to move further out of balance. If there is a feedback process, where downstream thinning causes further ungrounding and acceleration, then this could result in a major retreat of the ice stream.

\section{Appendix A}

\section{Brief summary of ICESat processing}

We use a $10 \mathrm{~km}$ radius around the GPS location to calculate the errors in the ICESat elevation change presented in this paper. This in every case incorporates several hundred ICESat elevation change values over the period 2003-2007 to give an average rate of change for this period. It makes the ICESat measurements more comparable with the previous ERS elevation change measurements, which have a much lower spatial resolution. Over this spatial range there is no bias caused by moving away from the glacier centerline. Therefore the errors are also valid when comparing the ICESat measurement to the current GPS measurements which are taken along the centerline.

We used ICESat GLA12 Release 28 data (Zwally et al., 2007) from 2003 up to November 2007. We fitted planar surfaces to parallel tracks of point height and date measurements that are close in space $(300 \mathrm{~m})$ and time ( 2 years). We then differenced the height and date of later point measurements that overlap these interpolated surfaces, giving us $\Delta h / \Delta t$. We repeated this process for all possible combinations of interpolated and overlapping tracks that fit our criteria. We estimate the uncertainty in our $\Delta h / \Delta t$ to be $\pm 0.07 \mathrm{ma}^{-1}$ at the 1-sigma level.

\section{A1 Methods}

\section{A1.1 Interpolation}

We used ICESat GLA12 Release 28 data (Zwally et al., 2007) (at the highest calibration level 4), for all available years from 2003 up to November 2007. To quantify elevation change, we began by grouping ICESat height measurements into two-year epochs (2003-2004, 2004-2005, 2005-2006 or 2006-2007). We interpolated surfaces between all elevation measurements in an epoch that have two neighbours lying within $300 \mathrm{~m}$ distance, using triangular irregular networks (TINs). This ensures an interpolation distance never greater than $260 \mathrm{~m}$, typically much shorter. For comparison, crossover analysis interpolates over $\sim 172 \mathrm{~m}$ and uses four points rather than our three. Our scheme produces long, ribbon-like, linearly-interpolated surfaces between closelyspaced, near-parallel tracks representing surface height for each epoch. To account for the difference in timing of the measurements, we performed the same interpolation on acquisition date.

Where these ribbon TINs were crossed by ground-track footprints from a later or earlier epoch, we extracted the interpolated elevation and acquisition date from the TIN at the new sample-point. This yields comparable elevation measurements: one interpolated, one measured precisely (crossover analysis compares pairs of interpolated heights), from which we calculated $\Delta h / \Delta t$. We repeated this for all possible date combinations forwards and backwards in time. The interval, $\Delta t$, ranges from 1 to 4.5 years, mean 728 days over Antarctica. Within a given epoch, this approach assumes linear elevation change both spatially between adjacent points, and through time. It sacrifices temporal resolution to gain spatial coverage.

\section{A1.2 Uncertainty estimate}

Our $\Delta h / \Delta t$ measurements are derived from height measurements largely corrected for pointing and saturation errors. We believe the residual uncertainty (1-sigma) is $<0.1 \mathrm{~m}$ (http://nsidc.org/data/icesat/detailed_disclaimer. html\#SatCorrNote). We assume forward scattering error to be temporally uncorrelated, affecting either the earlier or later data in a $\Delta h / \Delta t$ measurement, and so becomes random in sign. We filter out $\Delta h / \Delta t$ measurements that are anomalous relative to a large neighbourhood and assume a remaining forward-scattering uncertainty of $0.1 \mathrm{~m}$ (1-sigma). Our $\Delta h / \Delta t$ measurements come from combinations of typically 3 from 14 orbit periods assumed independent in error. From this budget, we estimate the combined $\Delta h / \Delta t$ uncertainty in our measurements to be $\pm 0.07 \mathrm{ma}^{-1}$ at the 1-sigma level. 
Acknowledgements. This work was supported by the Natural Environment Research Council, Geophysical Equipment Facility (Loan 847). We thank Feargal Buckley, Chris Griffiths, Rob Smith and Roger Stilwell for assistance with the fieldwork.

Edited by: J. L. Bamber

\section{References}

Anandakrishnan, S., Voigt, D. E., Alley, R. B., and King, M. A.: Ice stream D flow speed is strongly modulated by the tide beneath the Ross Ice Shelf, Geophys. Res. Lett., 30, 1361, doi:10.1029/2002GL016329, 2003.

Bindschadler, R. A., King, M. A., Alley, R. B., Anandakrishnan, S., and Padman, L.: Tidally controlled stick-slip discharge of a West Antarctic ice stream, Science, 301, 1087, doi:10.1126/science.1087231, 2003.

Dach, R., Beutler, G., and Gudmundsson, G. H.: Analysis of GPS data from an Antarctic ice stream, in: International Association of Geodesy Symposia, 133, Observing our Changing Earth, edited by: Sideris, M. G., Springer, Berlin Heidelberg, Germany, 569-579, doi:10.1007/978-3-540-85426-5_67, 2009.

Gudmundsson, G. H.: Tides and the flow of Rutford Ice Stream, West Antarctica, J. Geophys. Res., 112, F04007, doi:10.1029/2006JF000731, 2007.

Joughin, I., Rignot, E., Rosanova, C. E., Lucchitta, B. K., and Bohlander, J.: Timing of recent accelerations of Pine Island Glacier, Antarctica, Geophys. Res. Lett., 30, 1706, doi:10.1029/2003GL017609, 2003.

Paterson, W. S. B.: The Physics of Glaciers, Third Edition, Butterworth-Heinemann, Oxford, Great Britain, 1994.

Payne, A. J., Vieli. A., Shepherd, A. P., Wingham, D. J., and Rignot, E.: Recent dramatic thinning of largest West Antarctic ice stream triggered by oceans, Geophys. Res. Lett., 31, L23401, doi:10.1029/2004GL021284, 2004.
Pawlowicz, R., Beardsley, B., and Lentz, S.: Harmonic analysis including error estimates in MATLAB using T TIDE, Comput. Geosci., 28, 929-937, 2002.

Rignot, E.: Fast recession of a West Antarctic Glacier, Science, 281, 549-551, 1998.

Rignot, E.: Changes in ice dynamics and mass balance of the Antarctic ice sheet, Phil. Trans. R. Soc. A, 364, 1637-1655, doi:10.1098/rsta.2006.1793, 2006.

Rignot, E.: Changes in West Antarctic ice stream dynamics observed with ALOS PALSAR data, Geophys. Res. Lett., 35, L12505, doi:10.1029/2008GL033365, 2008.

Rignot, E., Vaughan, D. G., Schmeltz, M., Dupont, T., and MacAyeal, D.: Acceleration of Pine Island and Thwaites Glaciers, West Antarctica, Ann. Glaciol., 34, 189-193, 2002.

Shepherd, A., Wingham, D. J., and Mansley, J. A. D.: Inland thinning of the Amundsen Sea sector, West Antarctica, Geophys. Res. Lett., 29, 1364, doi:10.1029/2001GL014183, 2002.

Thomas, R., Rignot, E., Kanagaratnam, P., Krabill, W., and Casassa, G.: Force-peturbation analysis of Pine Island Glacier, Antarctica, suggests cause for recent acceleration, Ann. Glaciol., 39, 133138, 2004a.

Thomas, R., Rignot, E., Casassa, G., Kanagaratnam, P., Acuña, C., Akins, T., Brecher, H., Frederick, E., Gogineni, P., Krabill, W., Manizade, S., Ramamoorthy, H., Rivera, A., Russell, R., Sonntag, J., Swift, R., Yungel, J., and Zwally, J.: Accelerated Sea-Level Rise from West Antarctica, Science, 306, 255-258, doi:10.1126/science.1099650, 2004b.

Van der Veen, C. J.: Fundamentals of Glacier Dynamics, A. A. Balkema, Rotterdam, Netherlands, 1999.

Zwally, H. J., Schutz, R., Bentley, C., Bufton, J., Herring, T., Minster, J., Spinhirne, J., and Thomas, R.: GLAS/ICESat L2 Antarctic and Greenland Ice Sheet altimetry data V028, Boulder, CO, National Snow and Ice Data Centre, Digital media, 2007. 